\title{
Does the implementation of a national oral health policy reduce inequalities in oral health services utilization? The Brazilian experience
}

\author{
Maria Helena Rodrigues Galvão* (iD and Angelo Giuseppe Roncalli
}

\begin{abstract}
Background: This study aimed to assess the trend in income-related inequalities in oral health services utilization by the Brazilian population from 1998 to 2013. This period represents a timeline that includes different stages of implementation of the National Oral Health Policy.

Methods: The design was based on repeated cross-sectional surveys using secondary data from household-based studies carried out in Brazil in 1998, 2003, 2008, and 2013. The dependent variable was "having access to a dentist appointment at least once in a lifetime (yes/no)." Monthly household per capita income, based on Brazil's minimum wage, was included as the main independent variable. To measure the inequalities in oral health access related to economic position, the following complex indexes based on regression were used: (a) the slope index of inequality (SII) and (b) the relative index of inequality (RII).

Results: There was a reduction in the percentage of individuals who never had a dentist appointment for all age groups and income classifications. In general, there was a reduction trend in absolute inequality for all age groups $(p<0.001)$. The relative inequality and reduction trend were different between the age groups studied.

Conclusions: The National Oral Health Policy was very important for expanding free of charge, public access to dental appointment. However, despite policy implementation, there continues to be high levels of inequality in access to dental consultation. Assessing which strategies are necessary to overcome this challenge is discussed.
\end{abstract}

Keywords: Healthcare disparities, Oral health, Health policy

\section{Background}

The utilization of dental services is associated with many factors, including socioeconomic characteristics $[1,2]$. Inequalities in the use of dental services are seen globally and have resulted in limited access to dental care for billions of people [2]. The main strategy for mitigating these inequalities is the implementation of oral health policies. In general, these policies could improve access to dental

\footnotetext{
* Correspondence: mhrgalvao@gmail.com

Department of Dentistry, Federal University of Rio Grande do Norte, Natal, Rio Grande do Norte, Brazil
}

(c) The Author(s). 2021 Open Access This article is licensed under a Creative Commons Attribution 4.0 International License, which permits use, sharing, adaptation, distribution and reproduction in any medium or format, as long as you give appropriate credit to the original author(s) and the source, provide a link to the Creative Commons licence, and indicate if changes were made. The images or other third party material in this article are included in the article's Creative Commons licence, unless indicated otherwise in a credit line to the material. If material is not included in the article's Creative Commons licence and your intended use is not permitted by statutory regulation or exceeds the permitted use, you will need to obtain permission directly from the copyright holder. To view a copy of this licence, visit http://creativecommons.org/licenses/by/4.0/ The Creative Commons Public Domain Dedication waiver (http://creativecommons.org/publicdomain/zero/1.0/) applies to the data made available in this article, unless otherwise stated in a credit line to the data.

services, although it is most challenging to reduce the social and economic gradients in oral health care systems to produce a more egalitarian and just society [3].

In Brazil, health assistance is considered a citizenship right, being offered through a universal public health system guaranteed by the 1988 national constitution. Since 2004, Brazil has also developed a specific oral health policy, namely, the National Oral Health Policy (PNSB, in Portuguese), better known as Smiling Brazil (Brasil Sorridente, in Portuguese). This policy represents an innovative strategy focused on potentializing oral 
health care access across the country, among other initiatives. It is based on two different, but complementary strategies: increasing the number of oral health teams in primary care (especially in the Family Health Strategy) and expanding the secondary level of oral health care through the Centers of Specialized Dentistry (Centros de Especialidades Odontológicas - CEO, in Portuguese). The main objective of these two approaches is to increase integral health care, offering oral health services at different levels of complexity [4].

Since the implementation of this policy, an expansion in the number of oral health teams in primary care (ESB, from the Portuguese acronym) from 607 teams in 2003 to 25,905 in 2017 was observed, resulting in population coverage of $41.2 \%$. The population coverage is estimated by calculating the proportion of the population covered by ESB in relation to the whole population, considering a parameter of 3450 patients per provider determined by the Ministry of Health [5]. Regarding the expansion of secondary care, 1134 Centers of Specialized Dentistry (CEO) were established between 2004 and 2019, significantly increasing the availability of oral health services for the Brazilian population [6].

In relation to the oral health epidemiological profile, there was a decline in both prevalence and severity of dental caries, yet inequalities in distribution of these variables persisted in Brazil. This phenomenon was described by Antunes et al. [7] as "polarization of the caries experience." For adolescents, Roncalli et al. [8] observed that the significant reduction in dental caries observed between 2003 and 2010 was followed by an increase in inequality, meaning that there was a higher reduction in dental caries for the wealthy compared to the poor.

Regarding oral health care access, the last Brazilian National Health Survey (PNS, from the Portuguese acronym), conducted in 2013, showed that 112 million Brazilians (55.6\%) did not have access to oral health services in the 12 months prior to the interview. This percentage rose to $61.8 \%$ for Black people and to $63.4 \%$ for those without a formal education [9].

Despite the implementation of an oral health public policy as part of a universal health system, there is still a lack of knowledge about oral health care utilization by the Brazilian population, especially regarding socioeconomic inequalities.

Thus, this study aimed to assess the trend in incomerelated inequalities in oral health services utilization by the Brazilian population from 1998 to 2013. This period represents a timeline that includes the following stages in the implementation the National Oral Health Policy: 5 years before implementation (1998), the start of implementation (2003), and 5 years (2008) and 10 years (2013) after the first initiatives of Smiling Brazil.
Although it seems impossible to attribute changes in inequality trends uniquely to the implementation of the National Oral Health Policy, this type of analysis is fundamental to the establishment of strategies focused on a more equitable oral health care system.

\section{Methods}

The study was a secondary data analysis of responses from household-based repeated cross-sectional surveys carried out in Brazil. Data from the health supplement of the National Household Sample Survey (Pesquisa Nacional Por Amostra de Domicílios - PNAD, in Portuguese) of 1998, 2003, and 2008, and from the National Health Survey (Pesquisa Nacional de Saúde - PNS, in Portuguese) of 2013 were included. These data have national comprehensiveness and are representative of the Brazilian population. The four databases that were used consisted of a total sample of 1,327,223 participants. This study was conducted with information available to the public domain, through a dataset, thus ethical approval was not required. More details about the methods and data sources have been published elsewhere [9-12].

The datasets supporting the conclusions of this article are available on the website of the Brazilian Institute of Geography and Statistics (IBGE, in Portuguese). Table 1 presents the main characteristics of the household-based cross-sectional surveys.

The dependent variable selected was the answer to the question, "When did you last have a dentist appointment?" The response options were "less than 1 year," "1 year to 2 years," "3 or more years," or "never." These responses were then categorized as "Having access to a dentist appointment at least once in a lifetime (yes/no)." This outcome was selected due to the fact that it is an important question related to the use of dental services. Taking into account the recommendations for dental assistance $[13,14]$, responses to this question could reflect the absence of access.

Monthly household per capita income, based on Brazil's minimum wage, was used as the main independent variable. To create this variable, the original one named "amount of monthly household income" was divided by the number of residents. The original value of Brazilian currency (Reais) was converted into minimum wage, considering the value from the respective year. Finally, the income variable was categorized into five classifications: (1) up to 1.00 minimum wage; (2) 1.00 to 1.99 minimum wages; (3) 2.00 to 2.99 minimum wages; (4) 3.00 to 3.99 minimum wages; and (5) 4 minimum wages or more. Minimum wage was used as a criterion for income standardization because it is a national parameter and represents a social right guaranteed by the Brazilian national constitution. Its value is annually established by legal rules and should be able to supply the basic needs 
Table 1 Methodological characteristics of the surveys

\begin{tabular}{|c|c|c|c|c|}
\hline & \multicolumn{3}{|c|}{ National Household Sample Surveys (PNAD) } & \multirow{2}{*}{$\begin{array}{l}\text { National Health } \\
\text { Survey (PNS) } \\
2013\end{array}$} \\
\hline & 1998 & 2003 & 2008 & \\
\hline Number of individuals & 344,975 & 384,834 & 391,868 & 205,546 \\
\hline Number of households & 112,434 & 133,255 & 150,591 & $\begin{array}{l}81,767 \text { selected } \\
62,986 \text { interviewed }\end{array}$ \\
\hline Number of cities & 793 & 851 & 851 & $\begin{array}{l}6069 \text { Primary Sample } \\
\text { Units (PSU) }\end{array}$ \\
\hline Data collection period & September 1998 & September 2003 & September 2008 & July 2013 \\
\hline Sampling method & $\begin{array}{l}\text { Random sampling } \\
\text { of conglomerates }\end{array}$ & $\begin{array}{l}\text { Random sampling } \\
\text { of conglomerates }\end{array}$ & $\begin{array}{l}\text { Random sampling } \\
\text { of conglomerates }\end{array}$ & $\begin{array}{l}\text { Random sampling } \\
\text { of conglomerates }\end{array}$ \\
\hline
\end{tabular}

Source: Instituto Brasileiro de Geografia e Estatística

for life. The minimum wage in the selected survey years corresponded to 113 USD in 1998, 84 USD in 2003, 253 USD in 2008, and 317 USD in 2013, considering the currency variation in relation to the US dollar.

The analysis was stratified by age because this variable has an important influence on access to oral health services. Thus, four strata representing the different stages of the life course were created based on the World Health Organization groups: (a) children (0 to 9 years old), (b) adolescents (10 to 19 years old), (c) adults (20 to 59 years old), and (d) elderly (60 years and older).

The four surveys used a complex sample design with clustering defined by the primary sample unit (PSU) and a weight for each participant defined by the selection probability. To calculate the main estimates, the "survey data analysis" module of the software Stata 14 (svy command) was used, including the PSU and subject weight in the survey design for the dataset. Descriptive statistics were calculated, such as percentage frequencies and their respective 95\% confidence intervals, as well as the expansion of these estimates to the whole Brazilian population.

For measuring the inequalities in oral health access related to economic position, the following complex indexes for the assessment of health inequalities based on regression were used: (a) the slope index of inequality (SII), which estimates the absolute difference between the values of a health indicator in the most privileged and in the least privileged groups, taking into account the other groups, using a regression model, and (b) the relative index of inequality (RII), which estimates the ratio between the estimated values of a health indicator in the most privileged and in the least privileged groups, taking into account the other groups, using a linear regression model in this case, the exponentiated coefficient [15].

To illustrate the main results, Equiplots were drawn to demonstrate health inequalities in a given year. The Equiplot is a graphic representation of the trend in absolute inequality between groups, developed by the International Center for Equity in Health [16].

\section{Results}

Table 2 shows the population estimates for the lack of access to dentist appointments for the four age groups in the four survey years $(1998,2003,2008$, and 2013). In general, there was a reduction in the percentage of individuals who never had a dentist appointment for all groups and income classifications (Fig. 1).

Analyzing the inequality in access to dental services (Table 3), there was a reduction trend in absolute inequality for children. The SII was 54.2 in 1998 and 35.1 in 2013. The relative inequality in children, however, remained constant with an RII of 2.66 in 1998 and 2.31 in 2013. In adolescents, adults, and the elderly, there was a decreasing trend in absolute inequality between 1998 and 2008 with an increase in 2013. The RII for adolescents and adults showed an upward trend in relative inequality in 2003, with a decrease in subsequent years.

\section{Discussion}

The findings from the present study demonstrate that there was a reduction in the percentage of individuals who have never had a dentist appointment in Brazil during the survey periods. There was also a tendency toward reduction of absolute inequality, especially among children and adolescents, while there was a lower reduction in relative inequality with differences in these trends between the age groups. Despite this, the importance of income for access to oral health services was observed (i.e., the lower the income, the lower the frequency of having at least one dentist appointment in one's lifetime), regardless of the year assessed.

Scientific evidence for health inequalities is important to subsidize the process of planning and implementation of public health policies, which must include strategies to reduce the effect of social gradient on the distribution of health conditions [17]. Inequalities in oral health care utilization in Brazil were also revealed in a study conducted by Celeste et al. [18] that used data from oral health epidemiological surveys in Brazil in 1986 and 2003. A reduction in both absolute and relative 
Table 2 National estimates for never having access to a dentist appointment according to age group, per capita income, and year of study

\begin{tabular}{|c|c|c|c|c|c|c|c|c|c|}
\hline \multirow[t]{3}{*}{ Age group } & \multirow{3}{*}{$\begin{array}{l}\text { Household per } \\
\text { capita income }\end{array}$} & \multicolumn{8}{|c|}{ Individuals that never had access to a dentist appointment } \\
\hline & & \multicolumn{2}{|l|}{1998} & \multicolumn{2}{|l|}{2003} & \multicolumn{2}{|l|}{2008} & \multicolumn{2}{|l|}{2013} \\
\hline & & $\mathbf{n}$ & $\%(95 \% \mathrm{Cl})$ & $\mathbf{N}$ & $\%(95 \% \mathrm{Cl})$ & $\mathrm{n}$ & $\%(95 \% \mathrm{Cl})$ & $\mathbf{n}$ & $\%(95 \% \mathrm{Cl})$ \\
\hline \multirow[t]{6}{*}{ Up to 9 years-old } & Up to $1 \mathrm{MW}$ & 32,193 & $72.3(70.7-73.8)$ & 34,436 & $63.6(62.4-64.7)$ & 27,087 & $56.8(55.7-57.8)$ & 12,018 & $51.6(50.1-53.0)$ \\
\hline & 1 to $1.99 \mathrm{MW}$ & 5849 & $51.3(49.9-52.6)$ & 3879 & $44.2(42.9-45.5)$ & 3117 & $38.9(37.5-40.2)$ & 1644 & $37.2(34.9-39.7)$ \\
\hline & 2 to $2.99 \mathrm{MW}$ & 1606 & $45.4(42.4-48.4)$ & 937 & $35.3(33.0-37.6)$ & 765 & $34.9(32.7-37.2)$ & 413 & $30.2(26.3-34.4)$ \\
\hline & 3 to $3.99 \mathrm{MW}$ & 761 & $40.7(38.1-43.3)$ & 350 & $31.5(28.5-34.7)$ & 341 & $32.1(29.2-35.3)$ & 144 & $24.1(18.9-30.3)$ \\
\hline & $4 \mathrm{MW}$ and more & 1133 & $33.7(31.1-36.4)$ & 626 & $30.3(28.0-32.7)$ & 454 & $29.5(26.8-32.3)$ & 253 & $27.2(22.8-32.2)$ \\
\hline & Total & 41,542 & $64.0(62.2-65.8)$ & 40,228 & $58.1(57.0-59.2)$ & 31,764 & $52.3(51.3-53.2)$ & 14,472 & $46.8(45.6-48.1)$ \\
\hline \multirow[t]{6}{*}{ 10-19 years old } & Up to $1 \mathrm{MW}$ & 8451 & $25.4(23.7-27.3)$ & 10,103 & $20.0(18.7-21.2)$ & 6570 & $13.1(12.2-14.0)$ & 3425 & $11.8(10.9-12.9$ \\
\hline & 1 to $1.99 \mathrm{MW}$ & 875 & $7.3(6.6-8.0)$ & 600 & $4.7(4.2-5.2)$ & 385 & $2.9(2.6-3.3)$ & 245 & $2.9(2.2-3.7)$ \\
\hline & 2 to $2.99 \mathrm{MW}$ & 177 & $5.0(4.1-6.0)$ & 89 & $2.2(1.7-2.8)$ & 45 & $1.2(0.9-2.2)$ & 24 & $0.8(0.4-1.4)$ \\
\hline & 3 to $3.99 \mathrm{MW}$ & 66 & $3.1(2.4-3.9)$ & 26 & $1.3(0.8-2.0)$ & 12 & $1.0(0.5-2.0)$ & 5 & $2.3(0.5-9.5)$ \\
\hline & $4 \mathrm{MW}$ and more & 67 & $1.4(1.0-1.8)$ & 25 & $0.8(0.5-1.2)$ & 14 & $0.6(0.4-1.1)$ & 9 & $1.3(0.5-3.4)$ \\
\hline & Total & 9636 & $17.1(15.5-18.8)$ & 10,843 & $14.8(13.8-15.9)$ & 7026 & $9.9(9.2-10.7)$ & 3708 & $8.8(8.1-9.6)$ \\
\hline \multirow[t]{6}{*}{ 20-49 years old } & Up to $1 \mathrm{MW}$ & 5365 & $7.8(6.9-8.7)$ & 6635 & $6.5(6.0-7.1)$ & 4595 & $4.2(3.9-4.5)$ & 3071 & $5.0(4.6-5.6)$ \\
\hline & 1 to $1.99 \mathrm{MW}$ & 1153 & $2.7(2.4-3.1)$ & 969 & $2.0(1.8-2.2)$ & 762 & $1.3(1.2-1.5)$ & 579 & $1.5(1.3-1.8)$ \\
\hline & 2 to $2.99 \mathrm{MW}$ & 228 & $1.3(1.2-1.5)$ & 122 & $0.7(0.6-0.9)$ & 68 & $0.4(0.3-0.5)$ & 85 & $0.7(0.5-1.0)$ \\
\hline & 3 to $3.99 \mathrm{MW}$ & 90 & $0.9(0.7-1.3)$ & 30 & $0.4(0.2-0.6)$ & 30 & $0.4(0.3-0.6)$ & 25 & $0.3(0.1-0.5)$ \\
\hline & $4 \mathrm{MW}$ and more & 87 & $0.4(0.3-0.6)$ & 42 & $0.2(0.2-0.3)$ & 29 & $0.2(0.1-0.3)$ & 20 & $0.4(0.2-0.9)$ \\
\hline & Total & 6923 & $4.4(3.8-5.0)$ & 7798 & $4.0(3.6-4.4)$ & 5484 & $2.6(2.4-2.8)$ & 3780 & $3.0(2.8-3.3)$ \\
\hline \multirow[t]{6}{*}{60 years and older } & Up to $1 \mathrm{MW}$ & 936 & $11.2(10.0-12.5)$ & 1115 & $10.1(9.0-11.4)$ & 863 & $6.8(6.2-7.5)$ & 695 & $8.6(7.2-10.1)$ \\
\hline & 1 to $1.99 \mathrm{MW}$ & 639 & $6.8(5.9-7.8)$ & 747 & $5.8(5.1-6.5)$ & 631 & $3.7(3.4-4.1)$ & 447 & $4.2(3.5-5.0)$ \\
\hline & 2 to $2.99 \mathrm{MW}$ & 84 & $2.7(2.1-3.4)$ & 82 & $2.4(1.9-3.1)$ & 63 & $1.4(1.0-1.9)$ & 49 & $1.3(0.9-2.1)$ \\
\hline & 3 to $3.99 \mathrm{MW}$ & 22 & $1.3(0.7-2.3)$ & 21 & $1.1(0.7-1.9)$ & 14 & $0.5(0.3-0.9)$ & 13 & $0.7(0.2-2.3)$ \\
\hline & $4 \mathrm{MW}$ and more & 27 & $0.7(0.5-1.1)$ & 19 & $0.5(0.3-0.9)$ & 16 & $0.3(0.2-0.6)$ & 13 & $0.3(0.1-0.8)$ \\
\hline & Total & 1708 & 6.1 & 1984 & $6.0(5.3-6.6)$ & 1587 & $3.9(3.6-4.2)$ & 1217 & $4.8(4.2-5.5)$ \\
\hline \multirow[t]{6}{*}{ Total } & Up to $1 \mathrm{MW}$ & 48,705 & $29.3(28.2-30.5)$ & 52,289 & $23.5(22.7-24.3)$ & 39,115 & $17.6(17.1-18.2)$ & 19,209 & $12.8(12.2-13.4)$ \\
\hline & 1 to $1.99 \mathrm{MW}$ & 8799 & $11.1(10.7-11.6)$ & 6195 & $7.5(7.3-7.8)$ & 4895 & $5.3(5.1-5.5)$ & 2915 & $4.2(3.9-4.5)$ \\
\hline & 2 to $2.99 \mathrm{MW}$ & 2163 & $7.4(7.0-7.9)$ & 1230 & $4.4(4.1-4.7)$ & 941 & $3.2(3.0-3.5)$ & 571 & $2.3(2.0-2.6)$ \\
\hline & 3 to $3.99 \mathrm{MW}$ & 955 & $6.0(5.5-6.5)$ & 427 & $3.2(2.8-3.5)$ & 397 & $3.0(2.7-3.3)$ & 187 & $1.7(1.3-2.2)$ \\
\hline & $4 \mathrm{MW}$ and more & 1331 & $3.7(3.5-4.0)$ & 712 & $2.7(2.5-3.0)$ & 513 & $2.2(2.0-2.4)$ & 295 & $1.7(1.4-2.1)$ \\
\hline & Total & 61,953 & $18.9(17.6-20.3)$ & 60,853 & $16.0(15.4-16.7)$ & 45,681 & $11.9(11.4-12.3)$ & 23,177 & $8.2(7.9-8.6)$ \\
\hline
\end{tabular}

inequality over time was verified for the $35-44$ year old age group. A higher frequency of access for the wealthiest group was found and this effect persisted even after adjusting for confounding factors, such as gender and oral health condition measured by the decayed, missing, and filled teeth (DMF-T) index. Other oral health outcomes, such as self-perception of oral treatment needs, have been analyzed [19] and, in general, such an outcome has significant social determinants at both the individual and contextual levels [20].

Contextual factors have also been associated with the utilization of oral health services in Brazil. Vieira et al.
[21] applied multilevel modeling to study this association among adults living in capital cities, using data from the National Oral Health Survey (SBBrasil Project 2010) [22]. It was found that low income, low educational level, female gender, and self-reported race as Black or mixed were the main individual factors associated with lower utilization of oral health services, adjusted by the number of decayed teeth and oral health treatment needs. Similar to the present study, some studies developed in Brazil also used data from the PNAD surveys to assess inequalities in oral health care access and found trends in the reduction of inequalities between 2003 and 
(A)

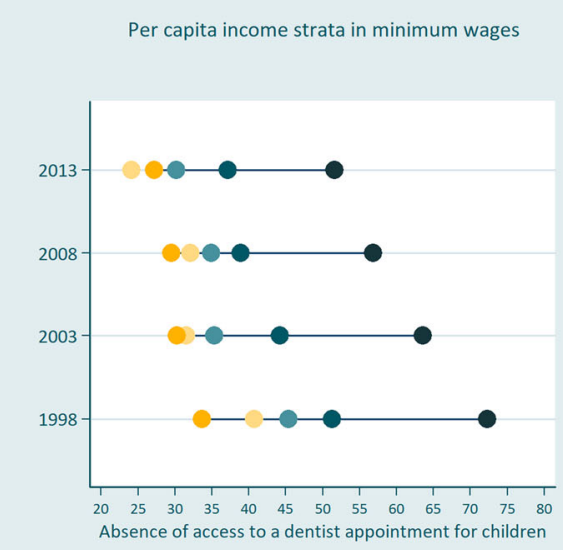

(C)

Per capita income strata in minimum wages

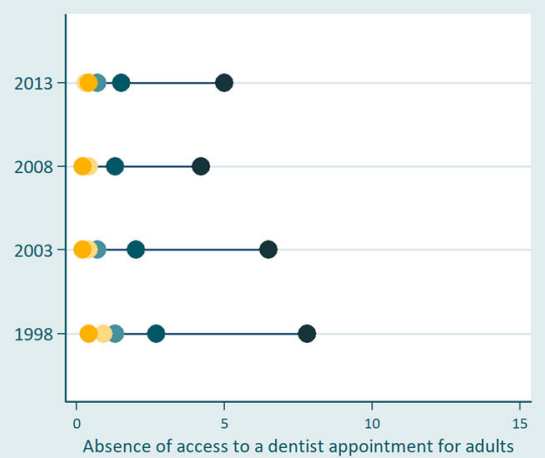

Absence of access to a dentist appointment for adults
(B)

Per capita income strata in minimum wages

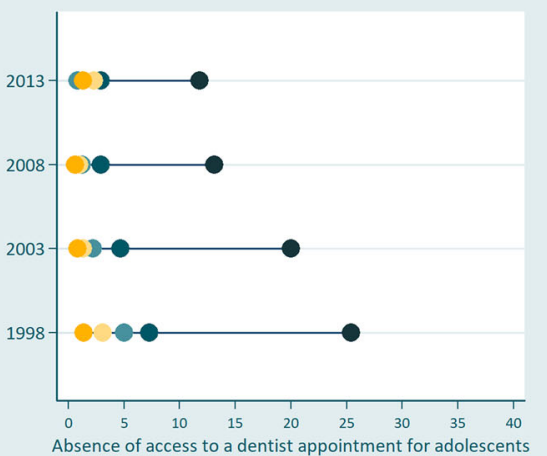

(D)

Per capita income strata in minimum wages

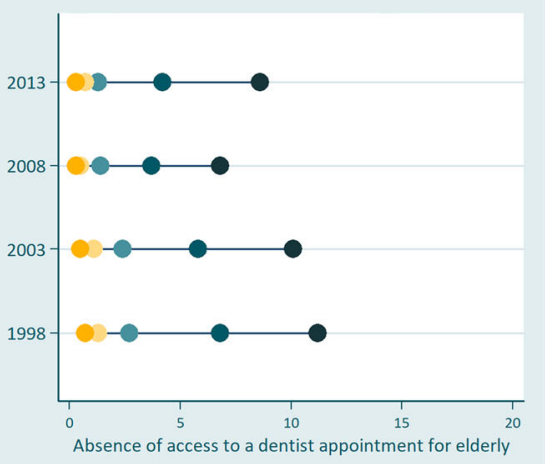

Up to $1 \mathrm{MW} \quad 1$ to $1.99 \mathrm{MW} \quad 2$ to $2.99 \mathrm{MW} \quad 3$ to $3.99 \mathrm{MW} \quad 4 \mathrm{MW}$ and more

Fig. 1 Equiplots for not having access to a dentist appointment at least once in a lifetime according to per capita income strata in Brazil from 1998 to 2013. a Children; b Adolescents; c Adults; d Elderly

Table 3 Slope Index of Inequality (SII) and Relative Index of Inequality (RII) for never having access to a dentist appointment

\begin{tabular}{|c|c|c|c|c|c|}
\hline Age group & 1998 & 2003 & 2008 & 2013 & $P$-value \\
\hline \multicolumn{6}{|c|}{ Slope Index of Inequality (95\% confidence interval (CI)) } \\
\hline Up to 9 years old & $54.20(51.93-56.56)$ & $50.78(48.46-53.10)$ & $39.94(37.58-42.31)$ & $35.06(31.88-38.22)$ & $<0.001$ \\
\hline 10-19years old & $31.60(30.92-32.28)$ & $17.67(17.02-18.31)$ & $18.20(17.72-18.67)$ & $19.17^{\mathrm{a}}(18.58-19.75)$ & $<0.001$ \\
\hline 20-49years old & $9.41(9.16-9.67)$ & $9.06^{\mathrm{a}}(8.86-9.26)$ & $5.93(5.77-6.09)$ & $7.17^{\mathrm{a}}(6.12-7.44)$ & $<0.001$ \\
\hline 60 years and older & $15.80(14.83-16.78)$ & $14.83(13.82-15.85)$ & $10.18(9.42-10.93)$ & $12.35(11.23-13.46)$ & $<0.001$ \\
\hline \multicolumn{6}{|c|}{ Relative Index of Inequality (95\%Cl) } \\
\hline Up to 9 years old & $2.66(2.53-2.79)$ & $2.80(2.65-2.97)$ & $2.42(2.28-2.57)$ & $2.31(2.11-2.52)$ & $<0.001$ \\
\hline 10-19years old & $27.06(24.06-30.44)$ & $41.77(35.50-49.16)$ & $40.10(31.61-49.30)$ & $26.19(20.08-34.16)$ & $<0.001$ \\
\hline 20-49years old & $24.07(21.33-27.16)$ & $30.81(26.97-35.20)$ & $27.17(23.27-31.74)$ & $18.40(15.49-21.85)$ & $<0.001$ \\
\hline 60 years and older & 11.59 (9.49-14.16) & $8.60(7.16-10.34)$ & $9.35(7.61-11.49)$ & $8.48(6.71-10.70)$ & $<0.001$ \\
\hline
\end{tabular}

The " $p$ " value indicates the significance for the time trend ${ }^{a}$ Convergence not achieved 
2008 [23, 24]. These studies also have indicated that there are other aspects that increase the vulnerability of the poorest people. For example, social status is a core factor related to access to social resources, such as formal education and employment, lower access to these resources could lead to a higher exposure to health risk factors [17].

An analysis of the age groups showed that the percentage of non-access, regardless of the year, was higher in children, then decreased in adolescents and adults, and rose slightly in the elderly. It is plausible to hypothesize that there is an expected trend of reduction in the outcome as age increases because a longer lifetime increases the probability of having access to at least one dentist appointment in one's lifetime. However, we did not observe this trend in the elderly. Although this result seems odd, it is important to highlight that this is a cross-sectional survey study, not a cohort study, which means that the elderly belong to a generation that had fewer opportunities for access to oral health care.

In any case, there was an increase in access to oral health services from 1998 to 2013. From the perspective of plausibility, it is important to highlight that there was an increase in the offer of public oral health services promoted by the PNSB during this period. As mentioned above, the main strategy of this policy was to expand access to public dental services for the whole country through the expansion of oral health teams (ESB) in primary care through the implementation of the Centers of Specialized Dentistry (CEO) in secondary care.

However, reducing the outcome does not guarantee a reduction in health inequalities. Although there has been general improvement in the population's access to dental services over the years, this improvement may have occurred more slowly for less privileged groups. Further, there may even have been a worsening of health conditions in this population. In some contexts, health policies contribute to the improvement of health indicators without reducing inequalities and, sometimes such improvements lead to the persistence of inequalities or even their expansion [17].

In children, high levels of absolute inequality were maintained, although there was a more pronounced reduction trend compared to other age groups, and relative inequality remained unchanged. This demonstrates that, although the policy promoted an increase in access to dental services for this age group, it may not be as effective for mitigating health inequalities in terms of promoting access for less privileged groups (Table 3).

In adolescents, the absolute inequality (SII) declined from 31.6 in 1998 to 18.2 in 2008 with a slight increase to 19.17 in 2013 . The relative inequality was higher in adolescents than in other age groups and similar levels were maintained during this period. The RII found in
2013 was 26.2, which means that among the poorest adolescents, the lack of access to dental care was 26.2 times higher than among the wealthiest adolescents (Table 3).

In adults, there was a lower absolute inequality among all other age groups. Although the reduction in absolute inequality was low, a more pronounced reduction was observed in relation to the relative inequality in comparison to the other age groups. In 2013, the prevalence of the outcome in adults was 18.4 times higher for the poorest (Table 3).

Finally, among the elderly, there was a trend toward decreasing absolute inequality between 1998 and 2008, returning to growth in 2013, where the poorest elderly people presented with a $12.4 \%$ greater lack of access than the richest elderly. There was a more pronounced reduction in relative inequality between 1998 and 2003 with similar values in other years. In general, the reduction in inequality was lower among the elderly, which could mean a minor impact of the expansion of access to dental services for this age group (Table 3).

An effective health policy should promote improvements in general health conditions for the population while achieving absolute and relative reductions in inequalities [17]. In the current study, we observed a limitation in the effect of the PNSB, such that, although it increased access to oral health services and consequently decreased the percentage of individuals who never had access to a dentist appointment, there is still room for improvement in overcoming existing income-related inequalities.

It is essential to recognize that contextual and individual characteristics influence the use of dental services. Some characteristics predispose people to use or not use such services, although these conditions are not directly responsible for utilization. Some characteristics are enabling facilitating the use of services, while other characteristics represent the need for utilization, which can be recognized by both the population and health professionals [25]. The implementation of the National Oral Health Policy, evaluated in this study, directly influenced enabling conditions, which facilitated in the financing and organization of services, while for other conditions, this policy had less influence.

In 2020, Brazil has 573 dental schools in operation [26]. Brazilian dentists represent about $12 \%$ of all professionals in the world [27], which shows that inequalities in the use of dental services are not related to the lack of suppliers. Moreover, it is relevant to consider that Brazil has a large number of dentists who work in the private sector, with assistance through direct payment and health insurance. In 2014, only $49.9 \%$ of Brazilian dentists worked in the public sector and were able to work in the private sector in the same period [28]. Thus, the 
use of dental services during the period analyzed in this study and hence the inequalities in utilization are also modulated by this market dynamic.

Two important aspects must be considered in relation to these findings. First, the PNSB's main objective was to promote an increase in the access to oral health services, and there was no specific strategy for reducing inequalities in care in the official documents. Second, there is a limited potential for a specific health policy to impact the comprehensive determinants of inequality. This requires strategies implemented by intersectoral policies that contribute to tackling the problem.

Therefore, the effect of public policies on the trend of inequality must also consider the evolution of the social indicators in Brazil. In addition to the increase in the minimum wage in this period, there was a reduction in income inequality, a significant decrease in poverty and food insecurity, and an increase in access to public services by the poorest and most vulnerable population, resulting in the improvement of several aspects of living conditions of the Brazilians population. Are observed a systematic reduction in income disparities indicator in the analyzed period, the highest since the beginning of its measurement in 1960. The evolution of these indicators, especially after 2003, cannot be credited only to economic factors such as the decrease in unemployment and an increase in the minimum wage. Mainly due to a deliberate effort by public policies such as "Brazil without poverty" (Brasil sem Miséria in Portuguese) and also cash transfer programs such as the Bolsa Família Program and the Continuous Benefit. Nevertheless, the socioeconomic gradient in a given year will always be an expression of inequality [29].

Beyond the need for reformulation to achieve better results, especially regarding the reduction of inequalities in access, the PNSB is not a state policy yet, and has suffered threats due to fiscal adjustment policies and progressive cuts in health resources. Additionally, several factors influenced the perceived importance of the PNSB at the federal level, aggravated by the minor importance of this policy gave by the government, which competes with supposed more relevant health policies [5].

One of the main features of the PNSB is the removal of barriers regarding the ability to pay for the use of dental consultations. The dental service is free of cost at the time of attendance, which differs from the oral health policies developed in some other countries. However, other barriers to access might impede the free utilization, such as geographical barriers, the larger demand for care, insufficient coverage of Family Health Teams in all territories, and the lack of both structure and supplies for dental assistance.

This study has strengths, such as its comprehensive feature, presenting a representative sample of the country during the period assessed. Furthermore, the sample was the result of national household-based surveys with a reliable sample design. Regarding data collection, methodological rigor and the use of validated and comparable instruments must be emphasized, which supports reliability of the data. The standardization of income strata based on the minimum wage in each year allowed comparability in the assessment of inequality. Moreover, the relevance of the assessment of socioeconomic inequalities in access to dental services must be highlighted during a period that is politically important for oral health care in Brazil.

Some limitations can be noted for this study. First, there may have been potential memory bias related to health services utilization, although this kind of bias is a core characteristic of any cross-sectional study using self-reported data. Another limitation is that we were unable to include other factors about oral health inequality due to their unavailability in these Brazilian datasets.

\section{Conclusions}

The findings demonstrate that there was a reduction in the percentage of individuals who never had access to a dentist appointment, as well as a reduction in the absolute inequality of this outcome 10 years after the implementation of the National Oral Health Policy. On the other hand, despite the policy implementation, the maintenance of high levels of relative inequality in access to dental consultation was observed.

Thus, it can be hypothesized that the National Oral Health Policy was very important for expanding public and free of charge access to dental consultation. However, at this stage of policy implementation, it is necessary to assess how policy implementation has contributed to the maintenance of high levels of inequality in access to dental consultation and which strategies are needed to overcome this challenge.

Thus, an important point for debate is the mitigating potential of health inequalities for universal measures focused on the expansion of access to dental care. This argument is based on the assumption that differences in access to dental services are unacceptable. Even though inequalities are mediated by economic position, they should not persist in a country that offers free public dental care with universal coverage. Health inequalities must be included in the political agenda, so that they are foreseen in the construction of more comprehensive policies for addressing the wider determinants of inequality.

\section{Abbreviations}

CEO: Centers of Specialized Dentistry; DMF-T: Decayed, missing, and filled teeth index; ESB: Oral health teams in primary care; IBGE: Brazilian Institute of Geography and Statistics; PNAD: National Household Sample Survey; PNS: Brazilian National Health Survey; PNSB: National Oral Health Policy; 
PSU: Primary sample unit; RII: Relative index of inequality; SBBrasil Project 2010: National Oral Health Survey; SII: Slope index of inequality

\section{Acknowledgments}

We thank Dr. Kenio Costa de Lima, Dr. Roger Keller Celeste and Dr. Franklin Soares Forte for the suggestions provided in the process of adapting this manuscript.

\section{Authors' contributions}

MHRG contributed to the conceptualization, statistical analysis, and writing of the original draft preparation. AGR contributed to the conceptualization, supervision, and writing (review and editing). All authors have read and approved the final version of this manuscript.

\section{Funding}

This study was financed in part by the Coordenação de Aperfeiçoamento de Pessoal de Nível Superior - Brasil (CAPES) - Finance Code 001. The funding consisted of a postgraduate studies scholarship and payment of publication fees. Furthermore, it did not interfere with the study's design and collection, analysis, and interpretation of data and writing the manuscript.

\section{Availability of data and materials}

The datasets supporting the conclusions of this article are available on the website of the Brazilian Institute of Geography and Statistics [https://www. ibge.gov.br/estatisticas/downloads-estatisticas.html].

\section{Declarations}

\section{Ethics approval and consent to participate}

Not applicable.

\section{Consent for publication}

Not applicable.

\section{Competing interests}

The authors declare that they have no competing interests.

Received: 23 July 2020 Accepted: 8 March 2021

Published online: 19 March 2021

\section{References}

1. Xu M, Cheng M, Gao X, Wu H, Ding M, Zhang C, Wang X, Feng X, Tai B, Hu D, Lin H, Wang B, Wang C, Zheng S, Liu X, Rong W, Wang W, Xu T, Si Y. Factors associated with oral health service utilization among adults and older adults in China, 2015-2016. Community Dent Oral Epidemiol. 2020; 48(1):32-41. https://doi.org/10.1111/cdoe.12497.

2. Reda SF, Reda SM, Thomson WM, Schwendicke F. Inequality in utilization of dental services: a systematic review and meta-analysis. Am J Public Health. 2018;108(2):e1-7. https://doi.org/10.2105/AJPH.2017.304180.

3. Watt RG. Social determinants of oral health inequalities: implications for action. Community Dent Oral Epidemiol. 2012;40(Suppl. 2):44-8. https://doi. org/10.1111/j.1600-0528.2012.00719.x.

4. Ministério da Saúde (Brazil). Diretrizes da Política Nacional de Saúde bucal. Brasília; 2004.

5. Lima CSCA, Almeida AMFL, Reis CS, Rossi TRA, Barros SG. Política de Saúde Bucal no Brasil: as transformações no período 2015-2017. Saúde Debate. 2018:42:76-91.

6. Ministério da Saúde (Brasil). Departamento de Informática do SUS- DATA SUS. Informações do Cadastro Nacional de Estabelecimentos de Saúde. 2019. http://cnes2.datasus.gov.br/Mod_Ind_Habilitacoes.asp?VEstado= 00\&VTipo=H. Accessed 28 Apr 2019

7. Antunes JLF, Toporcov TN, Bastos JL, Frazão P, Narvai PC, Peres MA. A saúde bucal na agenda de prioridades em saúde pública. Rev Saude Publica. 2016; 50:1-9.

8. Roncalli AG, Sheiham A, Tsakos G, Watt RG. Socially unequal improvements in dental caries levels in Brazilian adolescents between 2003 and 2010 Community Dent Oral Epidemiol. 2015;43(4):317-24. https://doi.org/10.1111/ cdoe.12156.

9. Instituto Brasileiro de Geografia e Estatística (Brasil). Pesquisa nacional de saúde 2013: acesso e utilização dos serviços de saúde, acidentes e violências. Rio de Janeiro; 2014
10. Instituto Brasileiro de Geografia e Estatística (Brasil). Pesquisa Nacional por Amostra de Domicílios- Acesso e utilização de serviços de saúde: 1998. Rio de Janeiro; 2000.

11. Instituto Brasileiro de Geografia e Estatística (Brasil). Pesquisa Nacional por Amostra de Domicílios- Acesso e utilização de serviços de saúde: 2003. Rio de Janeiro; 2005.

12. Instituto Brasileiro de Geografia e Estatística (Brasil). Pesquisa Nacional por Amostra de Domicílios: Um Panorama da Saúde no Brasil; acesso e utilização dos serviços, condições de saúde e fatores de risco e proteção à saúde 2008. Rio de Janeiro; 2010.

13. Scottish Dental Clinical Effectiveness Programme. Oral health assessment and review: guidance in brief. Dundee; 2011

14. American Academy of Pediatric Dentistry. Periodicity of examination, preventive dental services, anticipatory guidance/counseling, and oral treatment for infants, children, and adolescents. Pediatr Dent. 2017:39(6): 188-96.

15. World Health Organization (WHO). Health Equity Assessment Toolkit (HEAT): software for exploring and comparing health inequalities in countries. Geneva; 2017

16. Center For Equity In Health. Equiplot. http://www.equidade.org/equiplot php. Accessed 1 July 2019

17. Graham H, Kelly MP. Health inequalities: concepts, frameworks and policy. London: Health Development Agency; 2004

18. Celeste RK, Nadanovsky P, Fritzell J. Trends in socioeconomic disparities in the utilization of dental care in Brazil and Sweden. Scand J Public Health. 2011:39(6):640-8. https://doi.org/10.1177/1403494811414246.

19. Travassos C, Martins M. Uma revisão sobre os conceitos de acesso e utilização de serviços de saúde. Cad Saúde Pública. 2004;20:190-8.

20. Silva JV, Oliveira AGRC. Individual and contextual factors associated to the self-perception of oral health in Brazilian adults. Rev Saúde Pública. 2018;52: $1-12$

21. Vieira JMR, Rebelo MAB, Martins NMO, Gomes JFF, Vettore MV. Contextual and individual determinants of non-utilization of dental services among Brazilian adults. J Public Health Dent. 2019;79(1):60-70. https://doi.org/1 0.1111/jphd.12295

22. Ministério da Saúde (Brazil). Pesquisa Nacional de Saúde Bucal: resultados principais. Brasília; 2012

23. Barros AJD, Bertoldi AD. Desigualdades na utilização e no acesso a serviços odontológicos: uma avaliação em nível nacional. Ciênc Saúde Coletiva. 2002;7(4):709-17. https://doi.org/10.1590/S1413-81232002000400008.

24. Peres KG, Peres MA, Boing AF, Bertoldi AD, Bastos JL, Barros AJD. Reduction of social inequalities in utilization of dental care in Brazil from 1998 to 2008. Rev Saúde Pública. 2012;46(2):250-8. https://doi.org/10.1590/S0034-89102 012000200007.

25. Andersen RM. National health surveys and the behavioral model of health services use. Med Care. 2008;46(7):647-53. https://doi.org/10.1097/MLR. Ob013e31817a835d.

26. Federal Council of Dentistry. Statistical data of professionals and active entities by year - CFO. Available from: https://website.cfo.org.br/dados-esta tisticos-de-profissionais-e-entidades-ativas-por-ano/. Cited 2020 Dec 12.

27. Saliba NA, Moimaz SAS, Garbin CAS, Diniz DG. Dentistry in Brazil: its history and current trends. J Dent Educ. 2009;73(2):225-31. https://doi.org/10.1002/j. 0022-0337.2009.73.2.tb04658.x

28. Cascaes AM, Dotto L, Bomfim RA. Tendências da força de trabalho de cirurgiões-dentistas no Brasil, no período de 2007 a 2014: estudo de séries temporais com dados do Cadastro Nacional de Estabelecimentos de Saúde. Epidemiol Serv Saude. 2018;27:e201723615.

29. Jannuzzi PDM. Pobreza, Desigualdade e Mudança Social: trajetória no Brasil recente (1992 a 2014). Rev Estud e Pesqui sobre as Américas. 2016:10(3):29. https://doi.org/10.21057/repam.v10i3.21864.

\section{Publisher's Note}

Springer Nature remains neutral with regard to jurisdictional claims in published maps and institutional affiliations. 